\title{
Diagnostic and Prognostic Utility of Procalcitonin in Patients Presenting to the Emergency Department with Dyspnea
}

\author{
George A. Alba, MD, a Quynh A. Truong, MD, MPH, ${ }^{b}$ Hanna K. Gaggin, MD, MPH, ${ }^{c}$ Parul U. Gandhi, MD, ${ }^{c}$ \\ Benedetta De Berardinis, MD, ${ }^{d}$ Laura Magrini, MD, ${ }^{d}$ Ednan K. Bajwa, MD, MPH, ${ }^{a}$ Salvatore Di Somma, MD, PhD, ${ }^{d}$ \\ James L. Januzzi, Jr, MD, ${ }^{c}$ for the Global Research on Acute Conditions Team (GREAT) Network \\ ${ }^{a}$ Pulmonary and Critical Care Unit and ${ }^{c}$ Divison of Cardiology, Massachusetts General Hospital, Harvard Medical School, Boston; ${ }^{b}$ Dalio \\ Institute of Cardiovascular Imaging, New York-Presbyterian Hospital and Weill Cornell Medical College, New York; ${ }^{d}$ Emergency Medicine, \\ Department of Medical-Surgery Sciences and Translational Medicine, University Sapienza Rome, Sant'Andrea Hospital, Italy.
}

\begin{abstract}
BACKGROUND: Among patients in the emergency department, dyspnea is a common complaint and can pose a diagnostic challenge. Biomarkers are used increasingly to improve diagnostic accuracy and aid with prognostication in dyspneic patients. The purpose of this study was to examine the clinical utility of serum procalcitonin (PCT) for the diagnosis of pneumonia in patients presenting to the emergency department with dyspnea. A secondary objective was to evaluate the prognostic value of PCT for death to 1 year.

METHODS: This study pooled the patient populations of 2 prospective cohorts that previously enrolled patients presenting to 2 urban emergency departments with dyspnea. A total of 453 patients had serum samples available for biomarker analysis. Clinician certainty for the diagnosis of acutely decompensated heart failure was reviewed. Discrimination, calibration, and net reclassification improvement for the diagnosis of pneumonia as well as fatal outcomes were considered. The main outcome was accuracy of PCT for diagnostic categorization of pneumonia. The prognostic value of PCT for survival to 1 year was a secondary outcome.
\end{abstract}

RESULTS: Pneumonia alone was diagnosed in 30 patients $(6.6 \%)$, heart failure without pneumonia in 212 patients $(47 \%)$, and both diagnoses in 30 patients $(6.6 \%)$. Procalcitonin concentrations were higher in subjects with pneumonia $(0.38 \mathrm{vs} 0.06 \mathrm{ng} / \mathrm{mL} ; P<.001)$. Area under the receiver operating characteristic curve for the diagnosis of pneumonia based on PCT was 0.84 (95\% confidence interval [CI], 0.77-0.91; $P<.001)$. Across all levels of clinician-based estimates of heart failure, PCT was sensitive and specific; notably, in patients judged with diagnostic uncertainty $(\mathrm{n}=70)$, a PCT value of $0.10 \mathrm{ng} / \mathrm{mL}$ had the optimal balance of sensitivity and specificity ( $80 \%$ and $77 \%$, respectively) for pneumonia. Adding PCT results to variables predictive of pneumonia resulted in a net reclassification improvement of 0.54 (95\% CI, $0.24-0.83 ; P<.001)$ for both up- and down-reclassifying events. In adjusted analyses, elevated PCT was a predictor of 1-year mortality (hazard ratio $1.8 ; 95 \% \mathrm{CI}, 1.4-2.3 ; P<.001$ ) and was additive when elevated in conjunction with natriuretic peptides for this application.

CONCLUSION: In emergency department patients with acute dyspnea, PCT is an accurate diagnostic marker for pneumonia and adds independent prognostic information for 1-year mortality.

(C) 2016 Elsevier Inc. All rights reserved. • The American Journal of Medicine (2016) 129, 96-104

KEYWORDS: Dyspnea; Heart failure; Natriuretic peptides; Pneumonia; Procalcitonin

Funding: See last page of article.

Conflict of Interest: See last page of article.

Authorship: See last page of article.
Requests for reprints should be addressed to James L. Januzzi, Jr, MD, Massachusetts General Hospital, Cardiology Division, Yawkey 5984, 32 Fruit Street, Boston, MA 02114.

E-mail address: jjanuzzi@partners.org 
Of the 130 million annual visits to the emergency department, pneumonia and acutely decompensated heart failure rank among the top admitting diagnoses and represent the diagnoses with the largest number of 30-day all-cause readmissions, contributing to an estimated $\$ 4.3$ billion in annual hospital costs. ${ }^{1}$ In-hospital and 60- to 90-day mortality for heart failure are $8 \%$ and $13 \%$, respectively, ${ }^{2}$ and mortality is increased to $20 \%$ when a concomitant pneumonia is diagnosed. ${ }^{3}$ Many patients presenting with dyspnea have multiple coexisting medical disorders that complicate their diagnosis and management. Diagnostic uncertainty in this setting is associated with longer hospital length of stay, increased costs, and higher likelihood for repeat hospitalization or death. ${ }^{4}$ Further, delay of treatments, such as antibiotics in patients with pneumonia or diuretics for those with heart failure, has been associated with increased mortality. ${ }^{5,6}$ Consequently, early and accurate diagnosis is critical.

Studies have demonstrated that biomarkers may supplement judgment for diagnosis of heart failure ${ }^{7,8}$; for this application, the natriuretic peptides are now widely used. For correct diagnosis or exclusion of pneumonia, recent data have examined the potential value of procalcitonin (PCT). ${ }^{9,10}$

In healthy individuals, serum levels of PCT are undetectable. In states of bacterial infection, PCT messenger RNA is upregulated, whereas PCT production is attenuated by cytokines linked to viral infections ${ }^{11,12}$; PCT has thus been proposed as a diagnostic biomarker for bacterial infection. Although measurement of PCT has been examined in several clinical contexts, its use specifically in patients with acute dyspnea is less explored. In the Biomarkers in Acute Heart Failure (BACH) trial, data supportive of PCT to correctly identify or exclude pneumonia in patients with acute dyspnea were reported; additionally, PCT showed prognostic value for mortality prediction to 90 days from presentation. Therefore, we sought to rigorously examine the promising diagnostic and prognostic implications of PCT in patients with acute dyspnea.

\section{METHODS}

The institutional review boards at each institution approved of the study procedures (Partners Healthcare IRB, protocol no. 2003P000080).

\section{Study Population}

We examined the potential value of PCT in 2 populations of patients presenting to the emergency department setting, the
ProBNP Investigation of Dyspnea in the Emergency Department (PRIDE) study ${ }^{7}$ and the Biomonitoring and Cardiorenal Syndrome in Heart Failure (BIONICS-HF) study. ${ }^{13}$ A study flow diagram is demonstrated in Figure 1 .

The methods and primary results for the PRIDE study have been published previously. ${ }^{7}$ In the PRIDE Study (a single-center study of acute dyspnea performed in Boston, Mass), at the time of emergency department evaluation, clinicians were asked for their impression for the presence of heart failure on a continuous scale from 0 ("absolutely certain not present") to $100 \%$ ("absolutely certain to be present"). ${ }^{14}$ Analytes previously tested include amino-terminal pro-B type natriuretic peptide (NT-proBNP), mid-regional pro-atrial natriuretic peptide (MR-proANP), mid-regional pro-adrenomedullin (MR-proADM), ${ }^{15}$ and soluble (s)ST2.

The second cohort considered was the BIONICS-HF Study (NCT01570153). ${ }^{13}$ This population was drawn from consenting patients aged $\geq 18$ years who presented to the emergency department at either Massachusetts General Hospital (Boston) or Ospedale Sant'Andrea (Rome, Italy) with dyspnea due to heart failure. To be enrolled, the emergency department physician judged the patient as having certain heart failure.

As shown in Figure 1, from a potential total of 700 patients (599 patients from PRIDE and 101 patients from BIONICS-HF), 453 patients had available blood samples for biomarker analysis. Of these patients, $212(47 \%)$ had a final diagnosis of heart failure, $30(6.5 \%)$ had a primary diagnosis of pneumonia, and another $30(6.5 \%)$ of the patients with heart failure had a secondary diagnosis of pneumonia, bringing the total to $60(13 \%)$ patients with pneumonia. Follow-up to 1 year was $100 \%$ complete on all subjects in this analysis.

\section{Determination of Diagnosis}

The methods for determination of diagnosis have been published previously. ${ }^{7}$ The diagnosis of pneumonia was based on local medical records and subsequently crossverified according to clinical practice guidelines. ${ }^{16,17}$ Managing physicians and adjudicators were blind to natriuretic peptide and PCT results.

\section{Blood Analysis}

The NT-proBNP analysis was performed with a commercially available immunoassay (Elecsys proBNP; Roche Diagnostics, Indianapolis, Ind). ${ }^{7}$ Mid-regional-proANP, 


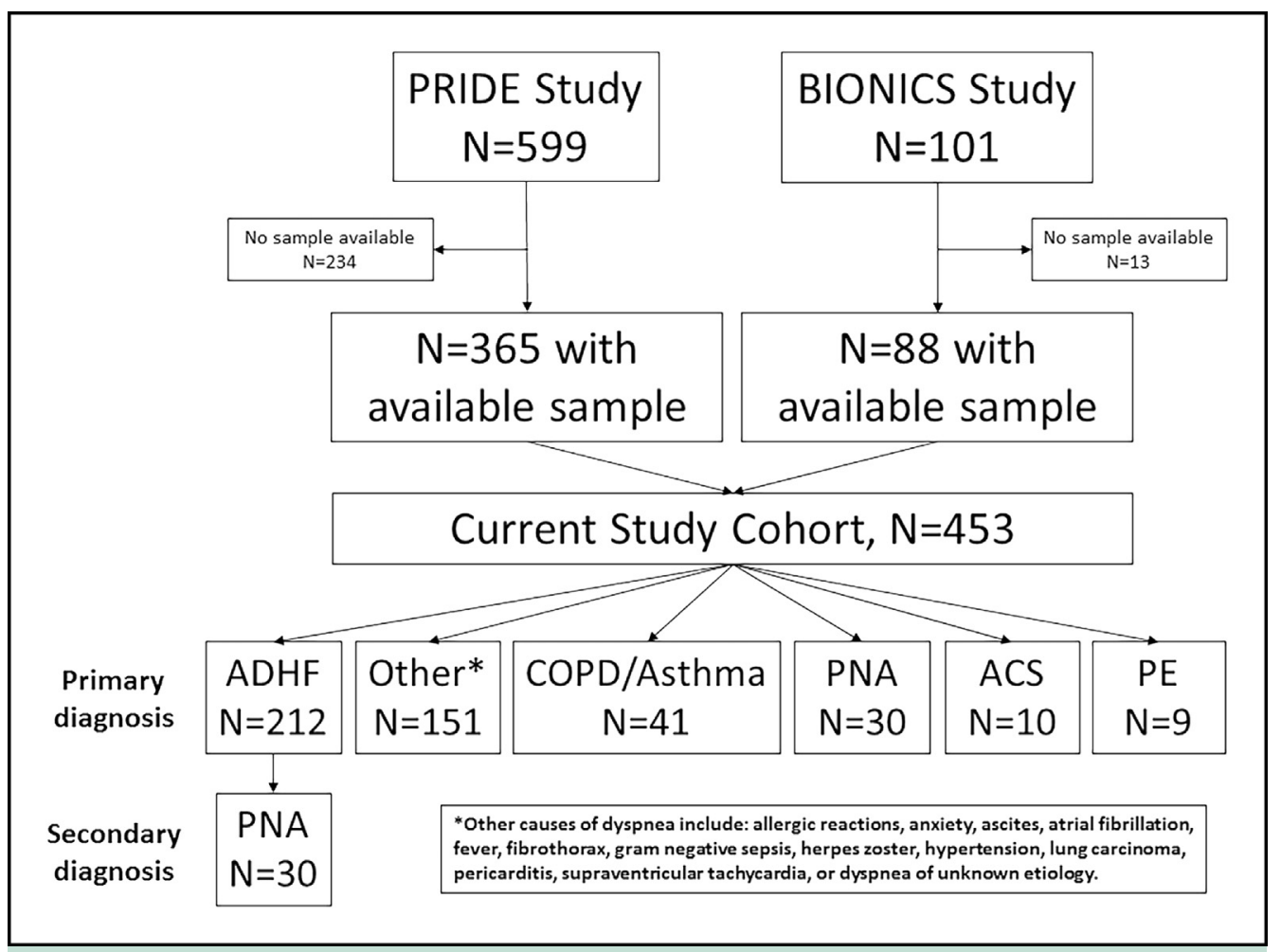

Figure 1 Flow diagram of the present study, including final diagnoses. ACS = acute coronary syndrome; $\mathrm{ADHF}=$ acutely decompensated heart failure; BIONICS = Biomonitoring and Cardiorenal Syndrome in Heart Failure; COPD = chronic obstructive pulmonary disease; $\mathrm{PE}=$ pulmonary embolism; PNA = pnuemonia; PRIDE = ProBNP Investigation of Dyspnea in the Emergency Department.

MR-proADM, and PCT were measured using a KRYPTOR System (BRAHMS AG, Hennigsdorf, Germany), whereas sST2 was assayed using a high-sensitivity enzyme-linked immunosorbent assay (Presage ST2; Critical Diagnostics, San Diego, Calif). The detection limit for PCT was $0.02 \mathrm{ng} / \mathrm{mL}$; interassay coefficients of variation for PCT concentrations $0.30 \mathrm{ng} / \mathrm{mL}$ are below $6 \%$. The intra-assay and interassay coefficients of variation for each marker have been reported previously. ${ }^{7,15}$

\section{Statistical Analysis}

Baseline characteristics of the study population, stratified by PCT concentration at presentation, were calculated. Continuous variables were summarized as mean \pm standard deviation if normally distributed, whereas non-normally distributed continuous variables were summarized as median and interquartile range. Kolmogorov-Smirnov testing identified states of non-normality. Variables were compared using the Student $t$ test or $\chi^{2}$ test as appropriate, whereas the Mann-Whitney $U$ test was used for continuous variables in the states of non-normality.

Diagnostic accuracy of PCT was assessed; performance of PCT at its optimal diagnostic threshold was assessed across clinician-expressed likelihood for the diagnosis of heart failure as the primary cause of dyspnea; as described by Green et al, ${ }^{14}$ results on this scale between $25 \%$ and $75 \%$ were defined as clinical uncertainty. In those patients with dyspnea and estimates $>75 \%$, clinicians were leaning toward heart failure, whereas by proxy a percent likelihood $<25 \%$ indicates clinical suspicion for an alternative diagnosis, such as pneumonia. Following this step, logistic regression models were developed to identify independent predictors of pneumonia. Odds ratios and $95 \%$ confidence intervals (CIs) were generated. All non-normal covariates were log-transformed. Logistic models were run for the multivariable model, once with PCT and once without PCT, with C-statistic for each step compared. After discrimination analysis, we considered continuous net reclassification improvement (NRI) as described by Pencina et al, ${ }^{18}$ using 999 bootstrap replications to estimate the $95 \%$ CI for NRI.

To identify independent predictors of mortality, we used stepwise Cox proportional hazards modeling, including clinical variables as well as log-transformed results for NTproBNP, MR-proANP, MR-proADM, sST2, and PCT. Variables with univariate significance $\leq .10$ were considered for the multivariable model. The proportion of hazards was checked. C-statistics for models with and without PCT were calculated, and NRI was again measured. Cumulative hazard curves with PCT alone as well as together with MR-proANP were constructed. Last, outcomes as a function of PCT result and antibiotic prescription were assessed. 
Table 1 Baseline Characteristics of the Study Subjects as a Function of Baseline Procalcitonin (PCT) Concentration

\begin{tabular}{|c|c|c|c|}
\hline Characteristic & $\begin{array}{l}\mathrm{PCT}<0.10 \mathrm{ng} / \mathrm{mL} \\
(\mathrm{n}=317)\end{array}$ & $\begin{array}{l}\mathrm{PCT} \geq 0.10 \mathrm{ng} / \mathrm{mL} \\
(\mathrm{n}=136)\end{array}$ & $P$ Value \\
\hline Age & $61.7 \pm 17.1$ & $72.7 \pm 12.7$ & $<.001$ \\
\hline Sex ( $\%$ male $)$ & $155(48.9)$ & $79(58.1)$ & .09 \\
\hline \multicolumn{4}{|l|}{ Past history } \\
\hline Diabetes mellitus & $89(28.1)$ & $54(39.7)$ & .02 \\
\hline Prior heart failure & $81(25.6)$ & $58(42.6)$ & $<.001$ \\
\hline Obstructive airway disease & $36(11.4)$ & $33(24.3)$ & .001 \\
\hline Hypertension & $162(51.1)$ & $93(68.4)$ & .001 \\
\hline Coronary artery disease & $95(30.0)$ & $54(39.7)$ & .06 \\
\hline Prior myocardial infarction & $48(15.1)$ & $28(20.6)$ & .20 \\
\hline \multicolumn{4}{|l|}{ Medications on presentation } \\
\hline$\beta$-Blocker & $140(44.2)$ & $75(55.1)$ & .04 \\
\hline Loop diuretic & $95(30.0)$ & $64(47.1)$ & .001 \\
\hline Digoxin & $29(9.1)$ & $18(13.2)$ & .30 \\
\hline ACE inhibitor & $73(23.0)$ & $34(25.0)$ & .70 \\
\hline Angiotensin II receptor blocker & $25(7.9)$ & $14(10.3)$ & .50 \\
\hline Aldosterone antagonist & $15(4.7)$ & $13(9.6)$ & .08 \\
\hline Aspirin & $120(37.9)$ & $57(41.9)$ & .50 \\
\hline Nitrate & $38(12.0)$ & $33(24.3)$ & .002 \\
\hline Inhaled short-acting $\beta$-agonist & $81(25.6)$ & $38(27.9)$ & .70 \\
\hline Advair & $25(7.9)$ & $23(16.9)$ & .007 \\
\hline Steroid, systemic & $16(5.0)$ & $5(3.7)$ & .70 \\
\hline Antibiotics, chronic & $4(1.3)$ & $6(4.4)$ & .07 \\
\hline Inhaled long-acting $\beta$-agonist & $13(4.1)$ & $10(7.4)$ & .20 \\
\hline Inhaled anticholinergic & $32(10.1)$ & $11(8.1)$ & .60 \\
\hline Combivent & $13(4.1)$ & $2(1.5)$ & .30 \\
\hline \multicolumn{4}{|l|}{ Symptoms } \\
\hline Paroxysmal nocturnal dyspnea & $44(13.9)$ & $25(18.4)$ & .30 \\
\hline Orthopnea & $69(21.8)$ & $49(36.0)$ & .002 \\
\hline Edema & $72(22.7)$ & $51(37.5)$ & .002 \\
\hline Chest pain & $135(42.6)$ & $37(27.2)$ & .003 \\
\hline Cough & $116(36.6)$ & $54(39.7)$ & .60 \\
\hline Fever & $21(7.5)$ & $19(22.4)$ & $<.001$ \\
\hline NYHA class & & & .002 \\
\hline I & $39(12.3)$ & $7(5.1)$ & \\
\hline II & $103(32.5)$ & $32(23.5)$ & \\
\hline III & $94(29.7)$ & $41(30.1)$ & \\
\hline IV & $81(25.6)$ & $56(41.2)$ & \\
\hline LVEF, last known & $57 \pm 17$ & $55 \pm 15$ & .07 \\
\hline \multicolumn{4}{|l|}{ Physical examination } \\
\hline Temperature $\left({ }^{\circ} \mathrm{F}\right)$ & $96.7 \pm 31.2$ & $98.1 \pm 30.7$ & .03 \\
\hline Body mass index $\left(\mathrm{kg} / \mathrm{m}^{2}\right)$ & $28.7 \pm 6.6$ & $28.5 \pm 8.1$ & .30 \\
\hline Heart rate (beats/min) & $84 \pm 22$ & $93 \pm 24$ & $<.001$ \\
\hline Systolic blood pressure $(\mathrm{mm} \mathrm{Hg})$ & $140 \pm 31$ & $137 \pm 40$ & .09 \\
\hline Jugular venous distension & $37(11.7)$ & $28(20.6)$ & .02 \\
\hline $\mathrm{S}_{3}$ gallop & $5(1.6)$ & $2(1.5)$ & 1.0 \\
\hline Rales & $89(28.1)$ & $80(58.8)$ & $<.001$ \\
\hline Edema & $92(29.1)$ & $63(46.3)$ & .001 \\
\hline \multicolumn{4}{|l|}{ Chest radiography } \\
\hline Interstitial edema & $55(17.4)$ & $49(36.0)$ & $<.001$ \\
\hline Infiltrate & $38(12.0)$ & $33(24.3)$ & .002 \\
\hline Cardiomegaly & $15(3.8)$ & $35(16.7)$ & $<.001$ \\
\hline Pleural effusion & $45(14.2)$ & $46(33.8)$ & $<.001$ \\
\hline \multicolumn{4}{|l|}{ Laboratory results, median (IQR) } \\
\hline GFR $\left(\mathrm{mL} / \mathrm{min} / 1.73 \mathrm{~m}^{2}\right)$ & $77.8(60.0-94.1)$ & $50.5(35.1-72.3)$ & $<.001$ \\
\hline WBC & $8.0(6.5-10.4)$ & $10.3(7.3-13.3)$ & $<.001$ \\
\hline Hemoglobin $(\mathrm{g} / \mathrm{dL})$ & $13.3(12.0-14.7)$ & $11.5(10.0-12.8)$ & $<.001$ \\
\hline NT-proBNP (pg/mL) & $388(72-2395)$ & $2685(910-10091)$ & $<.001$ \\
\hline
\end{tabular}


Table 1 Continued

\begin{tabular}{|c|c|c|c|}
\hline Characteristic & $\begin{array}{l}\mathrm{PCT}<0.10 \mathrm{ng} / \mathrm{mL} \\
(\mathrm{n}=317)\end{array}$ & $\begin{array}{l}\mathrm{PCT} \geq 0.10 \mathrm{ng} / \mathrm{mL} \\
(\mathrm{n}=136)\end{array}$ & $P$ Value \\
\hline MR-proANP (pmol/L) & $96.4(36.2-249.4)$ & $309.6(157.4-552.4)$ & $<.001$ \\
\hline $\mathrm{sST} 2(\mathrm{ng} / \mathrm{mL})$ & $23.5(13.7-44.3)$ & $97.7(51.0-190.1)$ & $<.001$ \\
\hline $\begin{array}{l}\text { Values are number (perc } \\
\text { ACE }=\text { angiotensin-con } \\
\text { MR-proADM = mid-regiona } \\
\text { natriuretic peptide; NYHA = }\end{array}$ & $\begin{array}{l}\text { ilation, unless otherv } \\
\text { ular filtration rate; } \\
\mathrm{P}=\text { mid-regional } p \\
\mathrm{~T} 2=\text { soluble } \mathrm{ST} 2 ; \mathrm{WE}\end{array}$ & $\begin{array}{l}\text { range; } \mathrm{LVEF}=\text { left ve } \\
\text { eptide; NT-proBNP }=\end{array}$ & $\begin{array}{l}\text { fraction; } \\
\text {-B type }\end{array}$ \\
\hline
\end{tabular}

Receiver operating characteristic (ROC) analyses were performed using Analyse It software (Leeds, United Kingdom), whereas all other statistical analyses were performed using either PASW Statistics, version 17.0 (Chicago, Ill) or SAS (version 9.2; SAS Institute, Cary, NC). All $P$ values are 2 -sided, with a value of $<.05$ considered significant.

\section{RESULTS}

As noted and depicted in Figure 1, of the 453 patients in the present study, $212(47 \%)$ had a final diagnosis of heart failure, $30(6.5 \%)$ had a primary diagnosis of pneumonia, and another $30(6.5 \%)$ of the patients with heart failure had a secondary diagnosis of pneumonia, bringing the total to 60 patients $(13 \%)$ with pneumonia.

\section{Baseline Characteristics}

A PCT value of $0.10 \mathrm{ng} / \mathrm{mL}$ was found to have the best testoperating characteristics for the diagnosis of pneumonia. Baseline characteristics of the study population stratified by PCT value of $<0.10$ or $\geq 0.10 \mathrm{ng} / \mathrm{mL}$ are detailed in Table 1.

\section{PCT and the Diagnosis of Pneumonia}

Median [interquartile range] concentrations of PCT were higher in those with pneumonia $(0.38[0.12-1.40] \mathrm{ng} / \mathrm{mL})$ compared with those without $(0.06$ [0.04-0.09] ng/mL; $P<.001$ for difference; Supplemental Figure 1, available online). Supplemental Figure 2 (available online) depicts the various diagnoses and PCT concentrations measured in the study cohort. Notably, PCT concentrations were particularly highest in those with comorbid heart failure and pneumonia (0.62 [0.28-3.20] ng/mL); conversely, those with both heart failure and pneumonia $(n=30)$ had the highest concentrations of natriuretic peptides (results not shown).

In ROC curves, PCT had an area under the curve (AUC) of 0.84 (95\% CI, 0.77-0.91; $P<.001$ ). An optimal PCT cutoff for the diagnosis of pneumonia was $0.10 \mathrm{ng} / \mathrm{mL}$; at this threshold, PCT had an excellent balance of sensitivity, specificity, positive predictive value, and negative predictive value (NPV), as shown in Table 2. Notably, across clinician estimates for heart failure, PCT performed consistently and in a manner consistent with Bayesian probabilities (Table 2): when clinician estimate for heart failure likelihood was $<25 \%$ (ie, less likely to be heart failure), PCT had highest specificity $(85 \%)$, whereas in those patients judged to have $>75 \%$ likelihood for heart failure $(\mathrm{n}=139)$, PCT had highest sensitivity $(95 \%)$ and NPV (99\%); more than half $(\mathrm{n}=74,53.2 \%)$ of subjects judged as high likelihood for heart failure had PCT values $<0.10 \mathrm{ng} / \mathrm{mL}$. Finally, in challenging cases when clinician estimate of heart failure likelihood was between $25 \%$ and $75 \%$ (defined as "indecision"), PCT had balanced sensitivity and specificity.

When examining patients a posteriori in those with heart failure, PCT had an AUC of 0.92 (95\% CI, 0.87-0.98; $P<.001$ ) for pneumonia; at $0.10 \mathrm{ng} / \mathrm{mL}$, PCT had $97 \%$ sensitivity, $69 \%$ specificity, $36 \%$ positive predictive value, and $99 \%$ NPV, confirming utility to exclude pneumonia in those with heart failure; the threshold providing comparable specificity (97\%) for pneumonia in heart failure was

Table 2 Operating Characteristics of Procalcitonin for the Diagnosis of Pneumonia in the Entire Group and in Previously Established Categories of Clinician-Estimated Likelihood for Heart Failure

\begin{tabular}{llll}
\hline Clinician Estimate of HF Likelihood & Sensitivity (\%) & Specificity (\%) & PPV (\%) \\
\hline Overall & 78 & 80 & 39 \\
Unlikely $(<25 \%), \mathrm{n}=244,33$ pneumonia & 70 & 85 & 96 \\
Uncertain $(25 \%-75 \%), \mathrm{n}=70,10$ pneumonia & 80 & 77 & 95 \\
Likely $(>75 \%), \mathrm{n}=139,17$ pneumonia & 95 & 57 & 36 \\
\hline
\end{tabular}

In patients judged with low likelihood for heart failure (hence higher likelihood for pulmonary diagnoses), procalcitonin (PCT) had highest specificity for pneumonia, whereas in those with high likelihood for heart failure, PCT had excellent negative predictive value (NPV) for pneumonia. In those judged with indecision, PCT had an optimal balance of sensitivity and specificity.

$\mathrm{HF}=$ heart failure; $\mathrm{NPV}=$ negative predictive value; $\mathrm{PPV}=$ positive predictive value. 
$0.40 \mathrm{ng} / \mathrm{mL}$. A possible strategy for using natriuretic peptides and PCT for evaluation of dyspnea is shown in Supplemental Figure 3 (available online).

In logistic regression to identify predictors of pneumonia, ln-transformed PCT remained as an independent variable in multivariable models (odds ratio 2.2; 95\% CI, 1.4-3.6; Table 3); univariate results for predictors of pneumonia are shown in Supplemental Table 1 (available online). The C-statistic of the base clinical model without PCT was 0.94 (95\% CI, 0.90-0.97), which rose to 0.95 (95\% CI, 0.91-0.98) after PCT was added $(P=.35)$.

Continuous NRI was performed comparing the model without PCT with a model incorporating PCT data. Addition of PCT results was associated with a significant NRI of 0.54 (95\% CI, 0.24-0.83; $P<.001$ ). Overall, the model including PCT moved $25 \%$ of pneumonia into a higher probability category $(P=.08)$, and $29 \%$ of non-pneumonia into a lower probability category $(P<.001)$.

\section{Predictors of Mortality}

There were 40 deaths during the first 90 days, and 80 deaths by 1 year. Concentrations of presentation PCT were higher in 9- day decedents compared with survivors (0.13 [0.08-0.41] vs 0.06 [0.04-0.10] ng/mL; $P<.001)$; in a similar manner, PCT values at presentation were higher in those dead at 1 year as well $(0.12[0.08-0.38]$ vs 0.06 [0.04-0.10] ng/mL; $P<.001)$.

Univariate predictors of death at 90 days and 1 year are shown in Supplemental Table 2; multivariable predictors of death at 1 year are shown in Supplemental Table 3 (both available online). At 90 days, in adjusted models, presence of a heart murmur on examination (hazard ratio [HR] 3.5; 95\% CI, 1.5-8.3; $P<.001)$ as well as ln-transformed concentrations of sST2 (HR 3.0; 95\% CI, $1.9-4.9 ; P<.001)$ emerged as predictors of 90 -day mortality. At 1 year, PCT was an independent predictor death in adjusted models (HR 1.8; 95\% CI, 1.4-2.3; $P<.001$ ), along with concentrations of MR-proANP (HR 1.8; 95\% CI 1.2-2.6; $P=.004)$.

To determine the incremental value of PCT beyond a base model, we again evaluated change in C-statistic; adding results for PCT increased the $\mathrm{C}$-statistic for mortality from 0.77 to $0.80(P=.02)$. Continuous NRI yielded a net reclassification improvement of $41 \%$ (95\% bootstrap CI, 8-74; $P<.001$ ), exclusively driven by down-classification of risk in $44 \%$.

In cumulative hazard analyses PCT $\geq 0.10 \mathrm{ng} / \mathrm{mL}$ was associated with higher cumulative hazard both at 90 days and 1 year (Figure 2). Because both PCT and MR-proANP were significant predictors of mortality at 1 year, we found greater precision in time to first event analyses considering the 2 in a multiple marker strategy using a previously derived threshold for MR-proANP $(\log$-rank $P<.001$; Supplemental Figure 4, available online). ${ }^{15}$

Of the patients with pneumonia, the great majority $(87.3 \%)$ were treated with antibiotics during their index hospitalization, whereas the minority $(25.1 \%)$ of those without pneumonia also were treated. We found no association between outcome as a function of PCT concentration at presentation and subsequent antibiotic prescription status. Changing PCT thresholds did not affect the results (results not shown).

\section{DISCUSSION}

Among patients with acute dyspnea in the emergency department setting, we found PCT provided good discrimination for the diagnosis and exclusion of pneumonia, and both up- and down-classified likelihood for pneumonia diagnosis. Importantly, PCT concentrations allowed for accurate diagnosis and exclusion of pneumonia in those patients with comorbid heart failure; early recognition and treatment of such patients is of importance given their higher risk. Finally, PCT values were prognostic for death by 1 year, showing additive value with MR-proANP for this application.

Biomarkers are used increasingly in the routine practice of clinical medicine. A burgeoning literature has demonstrated occasionally conflicting utility of PCT in the diagnosis and management of infectious syndromes including pneumonia. ${ }^{9,10,19-24}$ Our results are important, in that we not only showed that PCT provides useful discriminatory information for pneumonia, but does so in patients judged with clinical indecision, where PCT provided optimal operating characteristics. As would be expected on the basis

Table 3 Multivariable Predictors of a Diagnosis of Pneumonia Along with Operating Characteristics for the Diagnosis of Pneumonia

\begin{tabular}{|c|c|c|c|c|c|c|}
\hline Variable & Odds Ratio (95\% CI) & P Value & $\operatorname{Sn}(\%)$ & $\mathrm{Sp}(\%)$ & PPV $(\%)$ & NPV $(\%)$ \\
\hline Chest radiograph infiltrate or pneumonia & $12.5(4.6-34.1)$ & $<.001$ & 51 & 90 & 45 & 92 \\
\hline Fever & $4.3(1.5-12.7)$ & .009 & 38 & 93 & 47 & 92 \\
\hline PCT & $2.2(1.4-3.6)$ & .001 & 78 & 80 & 39 & 96 \\
\hline sST2 & $2.9(1.6-5.3)$ & $<.001$ & 81 & 68 & 29 & 96 \\
\hline
\end{tabular}

Both PCT and sST2 were entered as log-transformed variables. Operating characteristics for PCT and sST2 refer to optimal cut-offs of $0.10 \mathrm{ng} / \mathrm{mL}$ and 49 $\mathrm{ng} / \mathrm{mL}$, respectively.

$\mathrm{CI}=$ confidence intervals; NPV = negative predictive value; PCT = procalcitonin; PPV = positive predictive value; $\mathrm{Sn}=$ sensitivity; $\mathrm{Sp}=\mathrm{specificity;}$ sST2 = soluble ST2. 


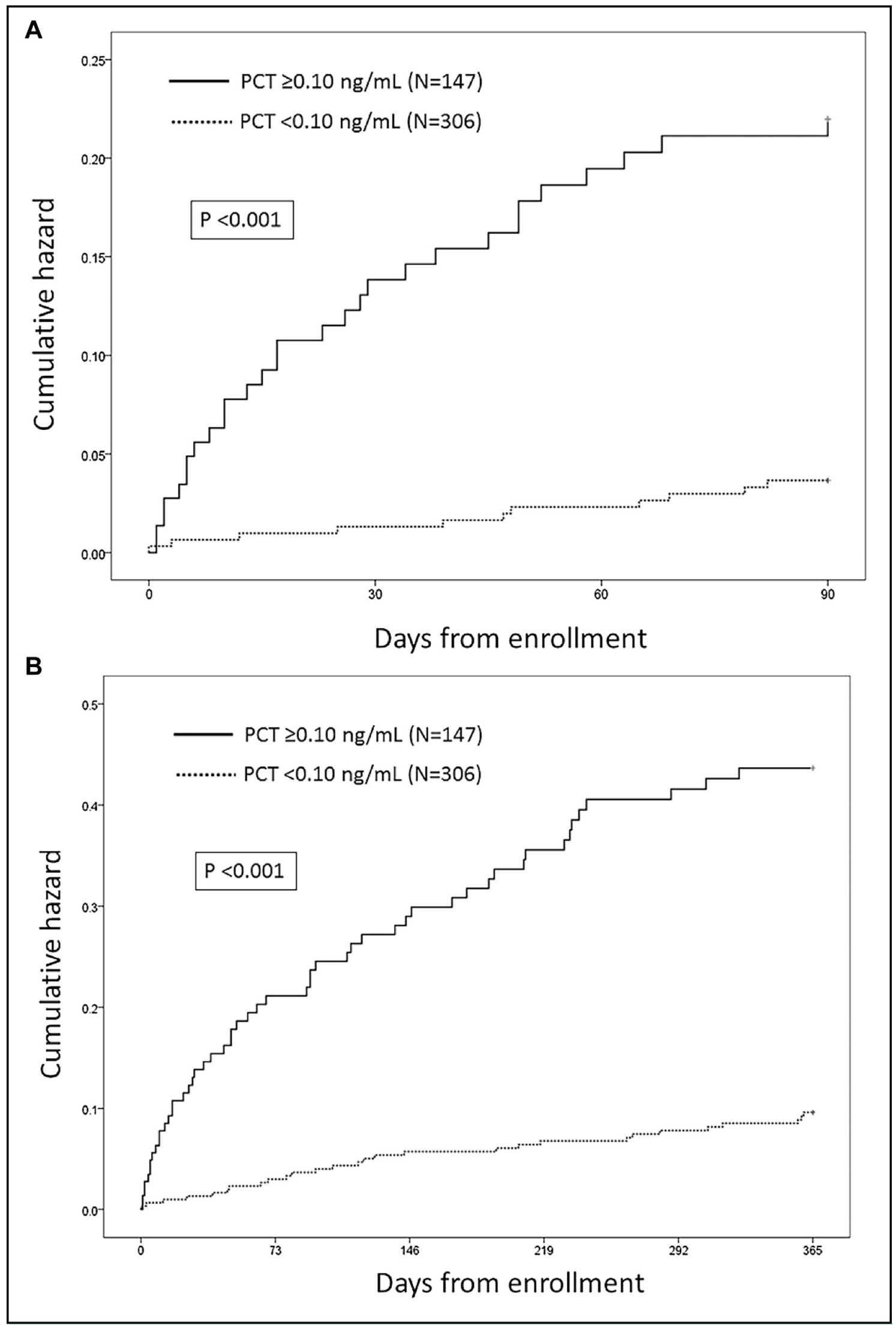

Figure 2 Cumulative hazard for death at (A) 90 days and (B) 1 year as a function of procalcitonin (PCT) concentrations. 
of Bayesian considerations, in those patients considered at high likelihood for heart failure, PCT was very sensitive (providing excellent NPV to exclude pneumonia in a majority of such subjects), whereas in those with a low likelihood for heart failure (hence high likelihood for a pulmonary diagnosis), an elevated PCT was highly specific for pneumonia.

A notable finding in our study was, when measured alone or together with MR-proANP in a multimarker strategy, higher PCT values were associated with shorter time to first event in cumulative hazards analysis. Pneumonia risk models such as the CURB-65 ${ }^{25}$ and Pneumonia Severity Index ${ }^{26}$ may be useful for triage decision making; however, their use may be cumbersome. Future efforts should compare the individual and additive value of PCT with established pneumonia risk scores; we lacked some variables in each model to examine this question in the present analysis.

Our results extend those of the BACH study with rigorous diagnostic and prognostic evaluation; although our findings are in alignment with $\mathrm{BACH}$, we found higher AUC in ROC analyses (0.84 vs 0.72 ) and also a greater degree of reclassification in NRI assessment. Importantly, we extend the BACH prognosis assessment of PCT by adding substantially more complicated diagnostic assessment in those with heart failure, more complex survival analyses that include discrimination and NRI and show value of PCT out to a follow-up to 1 year, as opposed to 90 days, and we also compared PCT with a broader range of contemporary biomarkers.

A limitation of our study is its modest size, which limits the power of statistical calculations. The number of patients diagnosed with pneumonia was low relative to the number of patients with heart failure. Although both cohorts were studied prospectively with a priori power assumptions for their respective primary outcomes, our retrospective analysis for our primary and secondary outcomes occurred a posteriori. We lack serial measurement of PCT or other biomarkers. Last, we had few patients with elevated PCT that went untreated with antibiotics.

\section{CONCLUSION}

In an era of increasing clinical complexity and healthcare costs, biomarkers represent an important tool for both diagnostic and prognostic efficiency. The potential role for PCT is broad-from predicting mortality risk to optimizing diagnostic accuracy for pneumonia and guiding antimicrobial use in patients with concomitant heart failure. Our results support the diagnostic and prognostic value of PCT in acute dyspnea, adding substantially to clinical variables and other biomarkers for these applications.

\section{ACKNOWLEDGMENTS}

The authors thank the Emergency Departments from our respective institutions for their support.

\section{References}

1. Hines AL, Barrett ML, Jiang HJ, Steiner CA. Conditions With the Largest Number of Adult Hospital Readmissions by Payer, 2011. Available at: www.ncbi.nlm.nih.gov/books/NBK206781/. Accessed October 26, 2014.

2. Rudiger A, Harjola VP, Müller A, et al. Acute heart failure: clinical presentation, one-year mortality and prognostic factors. Eur $J$ Heart Fail. 2005;7(4):662-670.

3. Fonarow GC, Abraham WT, Albert NM, et al. Factors identified as precipitating hospital admissions for heart failure and clinical outcomes: findings from OPTIMIZE-HF. Arch Intern Med. 2008;168(8):847-854.

4. Ray P, Birolleau S, Lefort Y, et al. Acute respiratory failure in the elderly: etiology, emergency diagnosis and prognosis. Crit Care. 2006;10(3):R82.

5. Kumar A, Ellis P, Arabi Y, et al. Initiation of inappropriate antimicrobial therapy results in a fivefold reduction of survival in human septic shock. Chest. 2009;136(5):1237-1248.

6. Meehan TP, Fine MJ, Krumholz HM, et al. Quality of care, process, and outcomes in elderly patients with pneumonia. JAMA. 1997;278(23):2080-2084.

7. Januzzi JL, Camargo CA, Anwaruddin S, et al. The N-Terminal Pro-BNP Investigation of Dyspnea in the Emergency Department (PRIDE) Study. Am J Cardiol. 2005;95(8):948-954.

8. Maisel AS, Krishnaswamy P, Nowak RM. Rapid measurement of B-type natriuretic peptide in the emergency diagnosis of heart failure. N Engl J Med. 2002;347(3):161-167.

9. Maisel A, Neath SX, Landsberg J, et al. Use of procalcitonin for the diagnosis of pneumonia in patients presenting with a chief complaint of dyspnoea: results from the BACH (Biomarkers in Acute Heart Failure) trial. Eur J Heart Fail. 2012;14(3):278-286.

10. Jensen JU, Hein L, Lundgren B, et al. Procalcitonin-guided interventions against infections to increase early appropriate antibiotics and improve survival in the intensive care unit: a randomized trial. Crit Care Med. 2011;39(9):2048-2058.

11. Linscheid P, Seboek D, Schaer DJ, Zulewski H, Keller U, Müller B. Expression and secretion of procalcitonin and calcitonin gene-related peptide by adherent monocytes and by macrophage-activated adipocytes. Crit Care Med. 2004;32:1715-1721.

12. Nijsten MW, Olinga P, The TH, de Vries EG. Procalcitonin behaves as a fast responding acute phase protein in vivo and in vitro. Crit Care Med. 2000;28(2):458-461.

13. De Berardinis B, Gaggin HK, Magrini L, et al. Comparison between admission natriuretic peptides, NGAL and sST2 testing for the prediction of worsening renal function in patients with acutely decompensated heart failure. Clin Chem Lab Med. 2015;53(4):613-621.

14. Green SM, Martinez-Rumayor A, Gregory SA, et al. Clinical uncertainty, diagnostic accuracy, and outcomes in emergency department patients presenting with dyspnea. Arch Intern Med. 2008;168(7):741-748.

15. Shah RV, Truong QA, Gaggin HK, Pfannkuche J, Hartmann O, Januzzi JL. Mid-regional pro-atrial natriuretic peptide and proadrenomedullin testing for the diagnostic and prognostic evaluation of patients with acute dyspnoea. Eur Heart J. 2012;33(17):2197-2205.

16. Martinez-Rumayor A, Camargo CA, Green SM, Baggish AL, O’Donoghue M, Januzzi JL. Soluble ST2 plasma concentrations predict 1-year mortality in acutely dyspneic emergency department patients with pulmonary disease. Am J Clin Pathol. 2008;130(4):578-584.

17. Mandell LA, Wunderink RG, Anzueto A, et al. Infectious Diseases Society of America/American Thoracic Society Consensus guidelines on the management of community-acquired pneumonia in adults. Clin Infect Dis. 2007;44(Suppl 2):S27-S72.

18. Pencina MJ, D'Agostino RB, Steyerberg EW. Extensions of net reclassification improvement calculations to measure usefulness of new biomarkers. Stat Med. 2011;30(1):11-21.

19. Tang BM, Eslick GD, Craig JC, McLean AS. Accuracy of procalcitonin for sepsis diagnosis in critically ill patients: systematic review and meta-analysis. Lancet Infect Dis. 2007;7(3):210-217. 
20. Wacker C, Prkno A, Brunkhorst FM, Schlattmann P. Procalcitonin as a diagnostic marker for sepsis: a systematic review and meta-analysis. Lancet Infect Dis. 2013;13(5):426-435.

21. Heyland DK, Johnson AP, Reynolds SC, Muscedere J. Procalcitonin for reduced antibiotic exposure in the critical care setting: a systematic review and an economic evaluation. Crit Care Med. 2011;39(7): 1792-1799.

22. Long W, Li L, Huang G, et al. Procalcitonin guidance for reduction of antibiotic use in patients hospitalized with severe acute exacerbations of asthma: a randomized controlled study with 12-month follow-up. Crit Care. 2014;18(5):471.

23. Christ-Crain M, Stolz D, Bingisser R, et al. Procalcitonin guidance of antibiotic therapy in community-acquired pneumonia: a randomized trial. Am J Respir Crit Care Med. 2006;174(1):84-93.

24. Schuetz P, Christ-Crain M, Thomann R, Falconnier C. Effect of procalcitonin-based guidelines vs standard guidelines on antibiotic use in lower respiratory tract infections. JAMA. 2009;302(10): 1059-1066.

25. Lim WS, Van der Eerden MM, Laing R, et al. Defining community acquired pneumonia severity on presentation to hospital: an international derivation and validation study. Thorax. 2003;58(5): 377-382.

26. Fine MJ, Auble TE, Yealy DM, et al. A prediction rule to identify lowrisk patients with community-acquired pneumonia. $N$ Engl J Med. 1997;336(4):243-250.

27. Baggish AL, van Kimmendade R, Bayes-Genis A, Davis M, et al. Hemoglobin and $\mathrm{N}$-terminal pro-brain natriuretic peptide: Independent and synergistic predictors of mortality in patients with acute heart failure: results from the International Collaborative of NT-proBNP (ICON) Study. Clin Chim Acta. 2007;381(2):145-150.

28. van Kimmendade R, Pinto YM, Bayes-Genis A, Lainchbury JG, Richards AM, Januzzi JL. Usefulness of intermediate aminoterminal prop-brain natriuretic peptide concentrations for diagnosis and prognosis of acute heart failure. Am J Cardiol. 2006;98(3): 386-390.

Funding: Sponsored by an unrestricted grant from Thermo Fisher Scientific.

Conflict of Interest: HKG has received grant support from Roche Diagnostics, and consulting income from Roche Diagnostics, American Regent/Lutipold Pharmaceuticals, and Critical Diagnostics. SDS has received consulting income from Thermo-Fisher. JLJ has received grant support from Siemens, Singulex, and Thermo-Fisher, consulting income from Roche Diagnostics, Critical Diagnostics, Spingotec, and Novartis, and serves on clinical endpoints committees for Amgen, Boeringer-Ingelheim, and Novartis.

Authorship: All authors had access to the data and a role in writing the manuscript.

\section{SUPPLEMENTAL DATA}

Supplemental figures and tables accompanying this article can be found in the online version at http://dx.doi.org/10. 1016/j.amjmed.2015.06.037. 


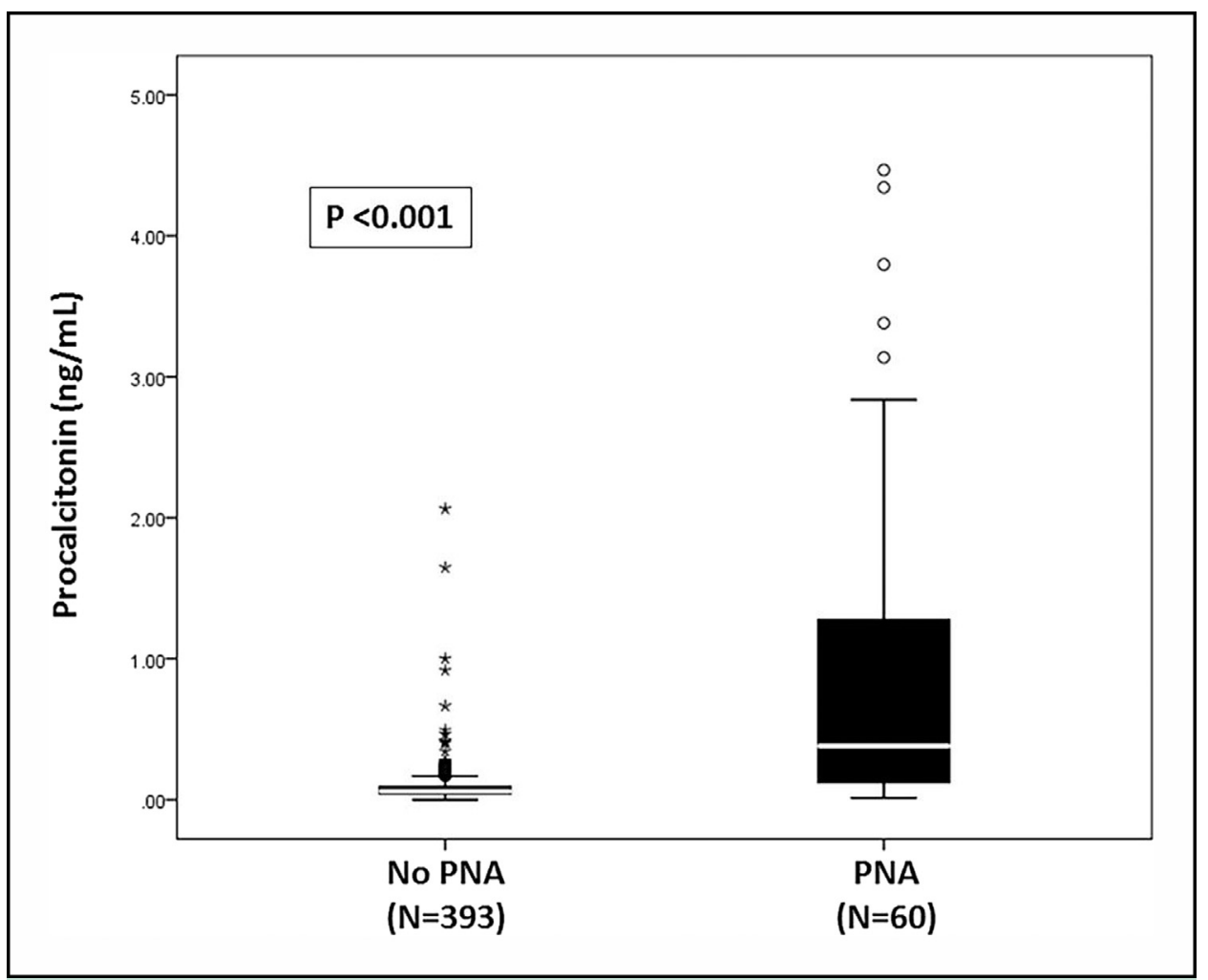

Supplemental Figure 1 Box and whisker plots of procalcitonin (PCT) as a function of pneumonia (PNA) vs alternative diagnosis. Median concentrations of procalcitonin were higher in those with pneumonia; boxes refer to the 25 th and 75 th percentiles, and whiskers the 5 th and 95 th percentiles. Outliers are shown as open circles, extremes as stars. 


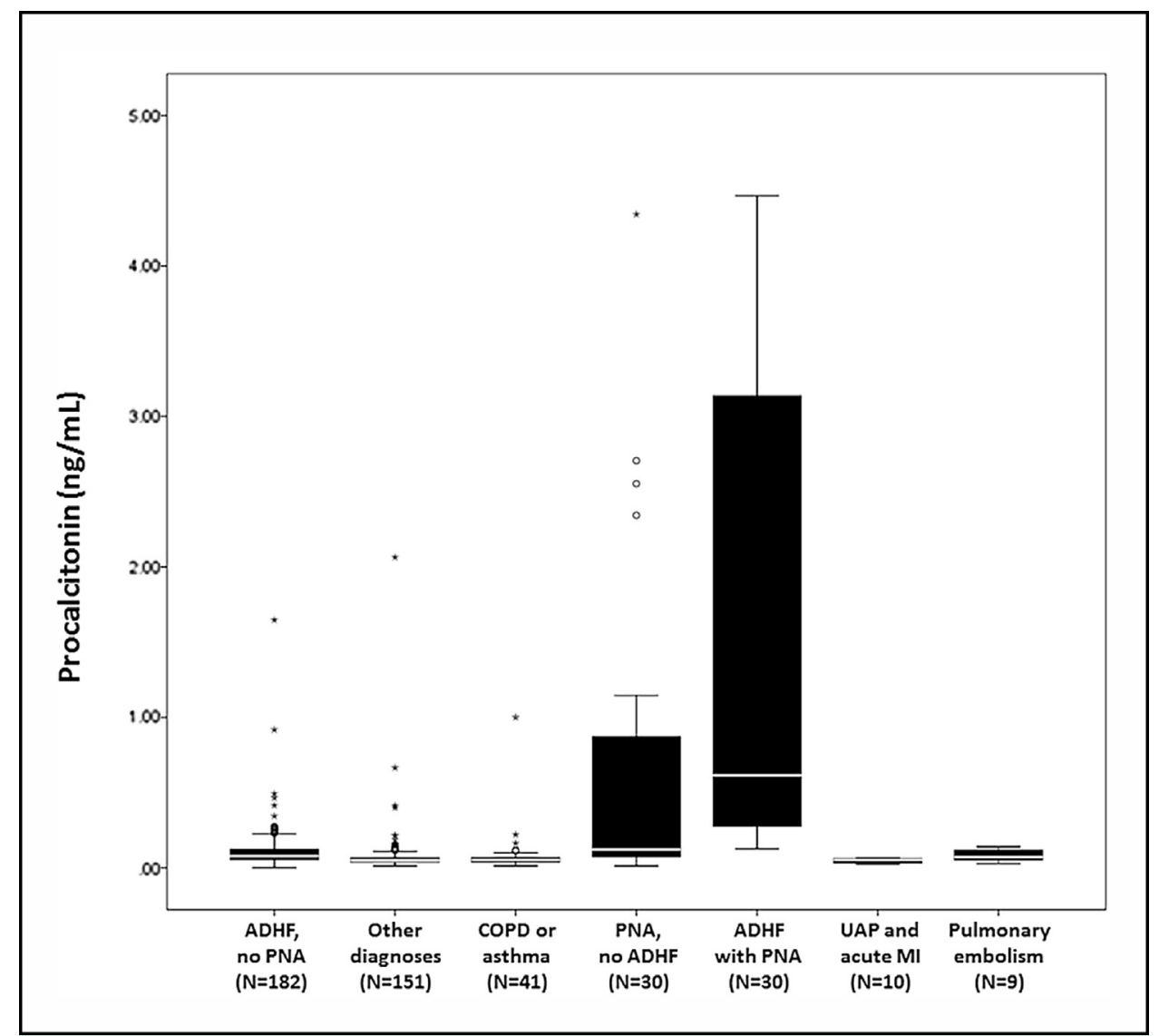

Supplemental Figure 2 Median concentrations of procalcitonin as a function of various diagnoses in the cohort. Values for procalcitonin were considerably higher in those with a diagnosis of pneumonia (PNA). Boxes refer to the 25th and 75th percentiles, and whiskers the 5th and 95th percentiles. Outliers are shown as open circles, extremes as stars. ADHF $=$ acutely decompensated heart failure; COPD = chronic obstructive pulmonary disease; $\mathrm{MI}=$ myocardial infarction; UAP = unstable angina pectoris. 


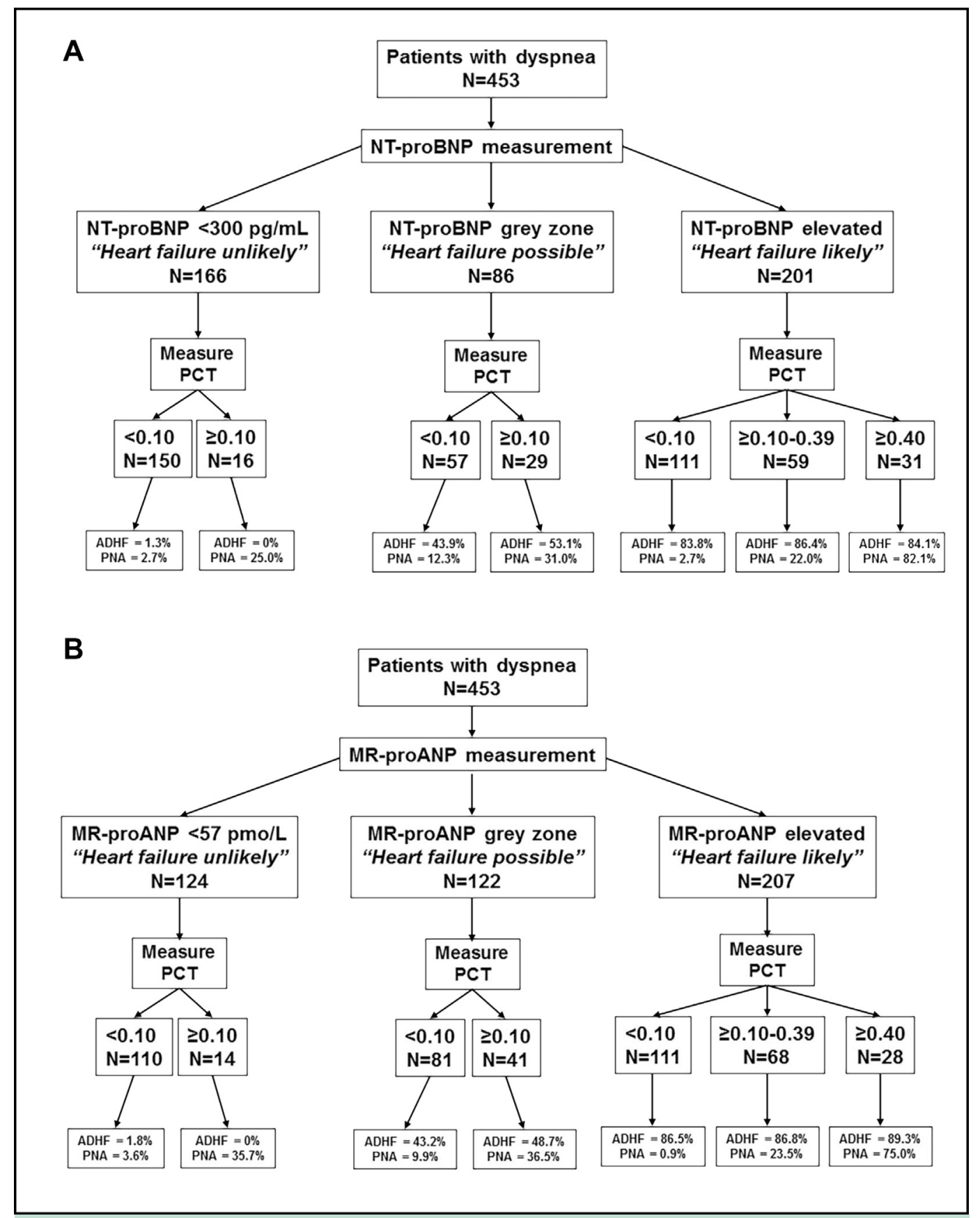

Supplemental Figure 3 Suggested diagnostic strategy for use of procalcitonin (PCT) in acute dyspnea, combining measurement with (A) amino-terminal pro-B type natriuretic peptide (NT-proBNP) or (B) mid-regional pro-atrial natriuretic peptide (MR-proANP). Using either natriuretic peptide, added use of procalcitonin allowed for even more refined identification or exclusion of heart failure (ADHF), pneumonia (PNA), or both diagnoses. Diagnostic cut-offs for NT-proBNP and MR-proANP are as previously defined. ${ }^{15,27,28}$ 


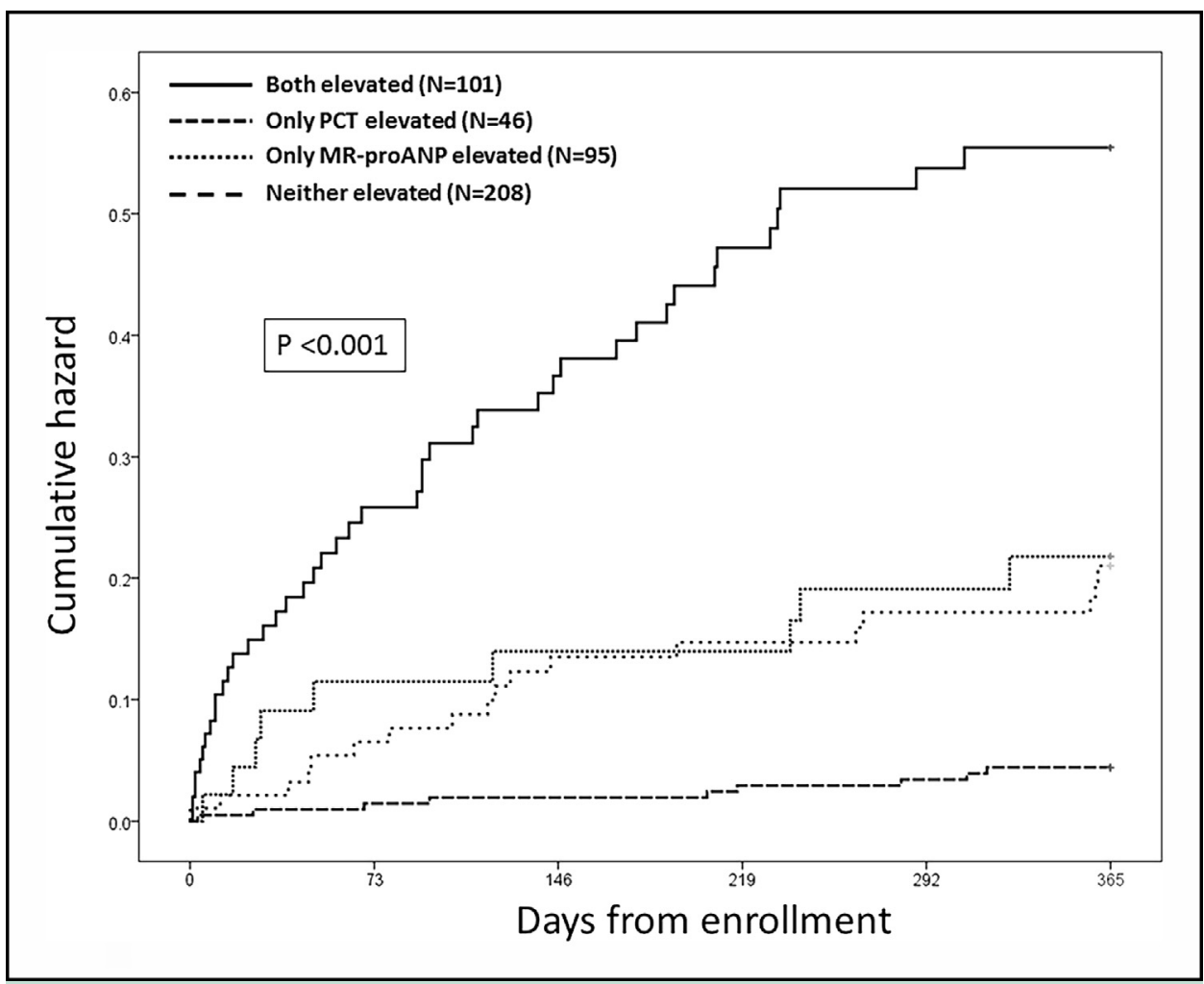

Supplemental Figure 4 Cumulative hazard for death at 1 year as a function of procalcitonin (PCT) and mid-regional pro-atrial natriuretic peptide (MR-proANP) concentrations. The 2 biomarkers provided additive prognostic value, reclassifying in time to first event analyses. 


\begin{tabular}{|c|c|c|}
\hline Univariate Variable & $\begin{array}{l}\text { Odds Ratio } \\
(95 \% \text { CI })\end{array}$ & $P$ Value \\
\hline ACE & $0.82(0.43-1.6)$ & .55 \\
\hline ARB & $0.49(0.15-1.6)$ & .25 \\
\hline ASA & $0.58(0.32-1.0)$ & .07 \\
\hline Acutely decompensated HF & $1.3(0.76-2.2)$ & .34 \\
\hline Advair & $2.0(0.97-4.2)$ & .06 \\
\hline Aldactone & $0.73(0.21-2.5)$ & .62 \\
\hline$\beta$-Blocker & $0.81(0.47-1.4)$ & .43 \\
\hline CXR infiltrate or pneumonia & $9.3(5.1-16.8)$ & $<.001^{*}$ \\
\hline CXR cephalization of vessels & $2.1(0.21-20.3)$ & .53 \\
\hline CXR interstitial edema & $1.5(0.86-2.8)$ & .15 \\
\hline CXR pleural effusion & $1.7(0.95-3.2)$ & .07 \\
\hline Chest pain & $0.42(0.22-0.79)$ & .007 \\
\hline Chronic antibiotics & $4.3(1.2-15.8)$ & .03 \\
\hline Combivent & $0.43(0.06-3.4)$ & .42 \\
\hline Cough & $3.0(1.7-5.1)$ & $<.001^{*}$ \\
\hline Digoxin & $1.3(0.58-2.9)$ & .52 \\
\hline ECG LBBB & $1.5(0.58-3.7)$ & .41 \\
\hline ECG LVH & $0.72(0.16-3.2)$ & .67 \\
\hline ECG atrial fib flutter & $1.8(0.96-3.5)$ & .07 \\
\hline ECG sinus rhythm & $0.64(0.37-1.1)$ & .11 \\
\hline Edema & $0.88(0.50-1.6)$ & .66 \\
\hline Fever & $8.0(3.9-16.7)$ & $<.001^{*}$ \\
\hline HCTZ & $0.58(0.17-2.0)$ & .38 \\
\hline HJR & $0.72(0.16-3.2)$ & .67 \\
\hline History of CAD & $0.72(0.40-1.3)$ & .28 \\
\hline History of COPD & $1.9(1.0-3.7)$ & .04 \\
\hline History of arrhythmia & $1.1(0.61-2.1)$ & .69 \\
\hline History of diabetes & $0.77(0.43-1.4)$ & .40 \\
\hline History of hypertension & $0.77(0.45-1.3)$ & .34 \\
\hline History of prior HF & $1.1(0.60-1.9)$ & .84 \\
\hline History of prior MI & $0.58(0.25-1.3)$ & .20 \\
\hline Hydralazine & $0.88(0.11-7.3)$ & .91 \\
\hline Inhaled anticholinergic & $1.7(0.79-3.8)$ & .17 \\
\hline Inhaled short acting $\beta$-agonist & $2.1(1.2-3.6)$ & .01 \\
\hline Inhaled corticosteroid & $2.0(0.85-4.5)$ & .12 \\
\hline Inhaled long acting $\beta$-agonist & $1.3(0.44-4.0)$ & .62 \\
\hline JVD & $0.85(0.38-1.9)$ & .69 \\
\hline Leukotriene modifier & $0.88(0.20-4.0)$ & .87 \\
\hline Loop diuretic & $0.99(0.57-1.7)$ & .97 \\
\hline Lower extremity edema & $0.46(0.23-0.94)$ & .03 \\
\hline Murmur & $0.85(0.37-2.0)$ & .70 \\
\hline Nitrate & $0.76(0.34-1.7)$ & .49 \\
\hline Orthopnea & $1.2(0.64-2.1)$ & .62 \\
\hline PND & $1.2(0.60-2.5)$ & .60 \\
\hline Pulmonary rales & $2.8(1.6-4.8)$ & $<.001^{*}$ \\
\hline S4Gallop & $1.2(0.14-10.8)$ & .84 \\
\hline Sex & $1.1(0.65-1.9)$ & .69 \\
\hline Systemic steroid & $2.6(0.98-7.1)$ & .05 \\
\hline Wheezing & $1.2(0.68-2.3)$ & .47 \\
\hline Age, log-transformed & $3.2(1.1-9.1)$ & .03 \\
\hline BMI, log-transformed & $0.34(0.10-1.2)$ & .09 \\
\hline NT-proBNP, log-transformed & $1.3(1.1-1.5)$ & $<.001^{*}$ \\
\hline BUN, log-transformed & $1.6(1.00-2.5)$ & .05 \\
\hline Creatinine, log-transformed & $2.3(1.2-4.3)$ & .01 \\
\hline
\end{tabular}

Supplemental Table 1 Continued

\begin{tabular}{|c|c|c|}
\hline Univariate Variable & $\begin{array}{l}\text { Odds Ratio } \\
(95 \% \text { CI })\end{array}$ & $P$ Value \\
\hline $\begin{array}{l}\text { MDRD creatinine clearance, } \\
\text { log-transformed }\end{array}$ & $0.49(0.29-0.83)$ & .008 \\
\hline Diastolic BP, log-transformed & $0.45(0.12-1.7)$ & .24 \\
\hline ECG QRS duration, log-transformed & $1.0(0.34-3.2)$ & .95 \\
\hline Glucose, log-transformed & $2.4(1.3-4.7)$ & .009 \\
\hline $\mathrm{Hb}$, log-transformed & $0.29(0.07-1.1)$ & .08 \\
\hline Last known EF, log-transformed & $0.58(0.26-1.3)$ & .18 \\
\hline PCT, log-transformed & $3.3(2.5-4.4)$ & $<.001$ \\
\hline MR proADM, log-transformed & $2.5(1.7-3.6)$ & $<.001^{*}$ \\
\hline MR proANP, log-transformed & $1.4(1.1-1.8)$ & .005 \\
\hline Pulse, log-transformed & $27.3(8.2-91.0)$ & $<.001^{*}$ \\
\hline Systolic BP, log-transformed & $0.32(0.12-0.89)$ & .03 \\
\hline Sodium, log-transformed & $1.9(0.22-15.6)$ & .56 \\
\hline ST2, log-transformed & $3.6(2.6-5.0)$ & $<.001^{*}$ \\
\hline WBC, log-transformed & $3.4(1.9-6.1)$ & $<.001^{*}$ \\
\hline NYHA: class II & $1.1(0.35-3.6)$ & .85 \\
\hline NYHA: class III & $1.3(0.41-4.2)$ & .65 \\
\hline NYHA: class IV & $3.1(1.0-9.2)$ & .05 \\
\hline NYHA: class I & 1.0 (reference) & - \\
\hline History of tobacco use: 1 & $0.33(0.14-0.79)$ & .01 \\
\hline History of tobacco use: 2 & $0.58(0.25-1.3)$ & .19 \\
\hline History of tobacco use: 3 & $0.51(0.20-1.3)$ & .17 \\
\hline History of tobacco use: 0 & 1.0 (reference) & - \\
\hline
\end{tabular}

$\mathrm{ACE}=$ angiotensin converting enzyme; $\mathrm{ARB}=$ angiotensin receptor blocker; $\mathrm{ASA}=$ aspirin; $\mathrm{BMI}=$ body mass index; $\mathrm{BP}=$ blood pressure; $\mathrm{BUN}$ $=$ blood urea nitrogen; $C A D=$ coronary artery disease; $C O P D=$ chronic obstructive pulmonary disease; CXR = chest $\mathrm{x}$-ray; $\mathrm{ECG}=$ electrocardiogram; $\mathrm{EF}=$ ejection fraction; $\mathrm{Hb}=$ hemoglobin; $\mathrm{HCTZ}=$ hydrochlorothiazide; $\mathrm{HF}=$ heart failure; $H J R=$ hepatojugular reflex; JVD = jugular venous distention; $\mathrm{LBBB}=$ left bundle branch block; $\mathrm{LVH}=$ left ventricular hypertrophy; $M D R D=$ Modification of Diet in Renal Disease; MI = myocardial infarction; NYHA $=$ New York Heart Association; PND = paroxysmal nocturnal dyspnea; $W B C=$ white blood cell. ${ }^{*}$ Indicates statistically significant. 
Supplemental Table 2 Univariate Predictors of Mortality at 90 Days and 1 Year

\begin{tabular}{|c|c|c|c|c|}
\hline Univariate Variable & $\begin{array}{l}\text { 90-Day Mortality } \\
\text { Hazard Ratio (95\% CI) }\end{array}$ & $\begin{array}{l}90 \text {-Day } \\
P \text { Value }\end{array}$ & $\begin{array}{l}\text { 1-Year Mortality } \\
\text { Hazard Ratio (95\% CI) }\end{array}$ & $\begin{array}{l}1 \text {-Year } \\
P \text { Value }\end{array}$ \\
\hline ACE & $1.4(0.72-2.8)$ & .32 & $1.2(0.72-1.9)$ & .51 \\
\hline ASA & $1.4(0.76-2.6)$ & .27 & $1.1(0.71-1.7)$ & .63 \\
\hline Acutely decompensated HF & $4.2(2.0-8.8)$ & $<.001^{*}$ & $3.9(2.3-6.4)$ & $<.001^{*}$ \\
\hline Advair & $1.2(0.47-3.1)$ & .71 & $1.2(0.63-2.4)$ & .54 \\
\hline CXR infiltrate or pneumonia & $2.1(1.1-4.3)$ & .03 & $1.3(0.76-2.3)$ & .32 \\
\hline CXR cephalization of vessels & 0 & .99 & $1.3(0.18-9.5)$ & .78 \\
\hline CXR interstitial edema & $3.3(1.8-6.1)$ & $<.001^{*}$ & $3.0(1.9-4.7)$ & $<.001^{*}$ \\
\hline CXR pleural effusion & $3.2(1.7-6.0)$ & $<.001^{*}$ & $2.7(1.7-4.3)$ & $<.001^{*}$ \\
\hline Chest pain & $0.60(0.30-1.2)$ & .16 & $0.76(0.48-1.2)$ & .26 \\
\hline ECG LBBB & $1.5(0.54-4.3)$ & .42 & $1.6(0.76-3.3)$ & .22 \\
\hline ECG LVH & $2.6(0.92-7.2)$ & .07 & $2.5(1.2-5.5)$ & .02 \\
\hline ECG atrial fib flutter & $1.9(0.91-3.8)$ & .09 & $1.8(1.1-2.9)$ & .03 \\
\hline ECG sinus rhythm & $0.39(0.21-0.72)$ & $.003^{*}$ & $0.56(0.36-0.88)$ & .01 \\
\hline Edema & $2.2(1.2-4.2)$ & .01 & $2.1(1.3-3.2)$ & .001 \\
\hline Fever & $1.8(0.63-5.5)$ & .27 & $1.8(0.88-3.7)$ & .11 \\
\hline $\mathrm{HCTZ}$ & $1.8(0.69-4.5)$ & .24 & $1.9(0.96-3.6)$ & .07 \\
\hline HJR & $3.5(1.4-8.8)$ & $.009^{*}$ & $2.6(1.2-5.7)$ & .01 \\
\hline History of CAD & $1.4(0.72-2.5)$ & .35 & $1.5(0.99-2.4)$ & .05 \\
\hline History of COPD & $1.2(0.52-2.7)$ & .70 & $1.2(0.67-2.1)$ & .55 \\
\hline History of arrhythmia & $1.8(0.92-3.4)$ & .09 & $1.7(1.1-2.8)$ & .02 \\
\hline Inhaled corticosteroid & $0.62(0.15-2.6)$ & .50 & $0.61(0.22-1.7)$ & .34 \\
\hline Inhaled long acting $\beta$-agonist & $0.46(0.06-3.4)$ & .45 & $0.96(0.35-2.6)$ & .94 \\
\hline JVD & $2.3(1.2-4.7)$ & .02 & $1.6(0.92-2.8)$ & .10 \\
\hline Leukotriene modifier & 0 & .99 & $0.32(0.04-2.3)$ & .26 \\
\hline Loop diuretic & $1.5(0.83-2.9)$ & .17 & $1.9(1.2-2.9)$ & .006 \\
\hline Lower extremity edema & $1.7(0.87-3.1)$ & .12 & $1.7(1.1-2.7)$ & .02 \\
\hline Murmur & $2.1(1.0-4.4)$ & .05 & $2.8(1.7-4.5)$ & $<.001^{*}$ \\
\hline Nitrate & $1.6(0.76-3.3)$ & .22 & $1.3(0.74-2.3)$ & .38 \\
\hline Orthopnea & $2.2(1.2-4.2)$ & .01 & $2.2(1.4-3.4)$ & $<.001^{*}$ \\
\hline PND & $1.2(0.52-2.6)$ & .70 & $1.5(0.90-2.6)$ & .12 \\
\hline Pulmonary rales & $3.0(1.6-5.6)$ & $<.001^{*}$ & $2.5(1.6-3.9)$ & $<.001^{*}$ \\
\hline S3Gallop & $5.8(1.8-18.9)$ & $.003^{*}$ & $4.8(1.8-13.2)$ & .002 \\
\hline Sex & $1.1(0.61-2.1)$ & .69 & $1.0(0.67-1.6)$ & .89 \\
\hline Systemic steroid & $0.52(0.07-3.8)$ & .52 & $1.7(0.74-3.9)$ & .21 \\
\hline Wheezing & $0.57(0.24-1.3)$ & .20 & $0.72(0.41-1.3)$ & .26 \\
\hline Age, log-transformed & $22.8(4.0-129.5)$ & $<.001^{*}$ & $17.8(5.5-57.7)$ & $<.001^{*}$ \\
\hline BMI, log-transformed & $0.20(0.05-0.89)$ & .03 & $0.37(0.14-1.0)$ & .06 \\
\hline NT-proBNP, log-transformed & $1.5(1.2-1.8)$ & $<.001^{*}$ & $1.5(1.3-1.7)$ & $<.001^{*}$ \\
\hline BUN, log-transformed & $2.6(1.5-4.4)$ & $<.001^{*}$ & $2.6(1.8-3.7)$ & $<.001^{*}$ \\
\hline Creatinine, log-transformed & $1.9(0.91-3.9)$ & .09 & $2.2(1.3-3.6)$ & .003 \\
\hline MDRD creatinine clearance, log-transformed & $0.50(0.28-0.89)$ & .02 & $0.45(0.30-0.66)$ & $<.001^{*}$ \\
\hline Diastolic BP, log-transformed & $0.50(0.11-2.3)$ & .38 & $0.34(0.11-1.0)$ & .05 \\
\hline
\end{tabular}


Supplemental Table 2 Continued

\begin{tabular}{|c|c|c|c|c|}
\hline Univariate Variable & $\begin{array}{l}\text { 90-Day Mortality } \\
\text { Hazard Ratio (95\% CI) }\end{array}$ & $\begin{array}{l}90 \text {-Day } \\
P \text { Value }\end{array}$ & $\begin{array}{l}\text { 1-Year Mortality } \\
\text { Hazard Ratio }(95 \% \text { CI) }\end{array}$ & $\begin{array}{l}\text { 1-Year } \\
P \text { Value }\end{array}$ \\
\hline ECG QRS duration, log-transformed & $2.7(0.81-9.2)$ & .10 & $2.2(0.97-5.2)$ & .06 \\
\hline $\mathrm{Hb}$, log-transformed & $0.14(0.04-0.52)$ & .003 & $0.12(0.05-0.29)$ & $<.001^{*}$ \\
\hline Last known EF, log-transformed & $0.39(0.19-0.83)$ & .01 & $0.58(0.33-1.0)$ & .06 \\
\hline PCT, log-transformed & $1.5(1.3-1.8)$ & $<.001^{*}$ & $1.5(1.3-1.7)$ & $<.001^{*}$ \\
\hline Pulse, log-transformed & $3.5(1.0-12.0)$ & .04 & $1.8(0.78-4.1)$ & .17 \\
\hline Systolic BP, log-transformed & $0.64(0.22-1.8)$ & .40 & $0.56(0.29-1.1)$ & .09 \\
\hline Sodium, log-transformed & $1.2(0.36-4.0)$ & .77 & $0.82(0.54-1.2)$ & .34 \\
\hline ST2, log-transformed & $2.6(1.9-3.5)$ & $<.001^{*}$ & $2.2(1.8-2.7)$ & $<.001^{*}$ \\
\hline WBC, log-transformed & $1.8(0.99-3.2)$ & .05 & $1.4(0.86-2.1)$ & .19 \\
\hline History of tobacco use: 1 & $0.34(0.15-0.79)$ & .01 & $0.46(0.24-0.88)$ & .02 \\
\hline History of tobacco use: 2 & $0.24(0.10-0.60)$ & .002 & $0.42(0.22-0.81)$ & .01 \\
\hline History of tobacco use: 3 & $0.36(0.14-0.98)$ & .05 & $0.42(0.19-0.91)$ & .03 \\
\hline History of tobacco use: 0 & 1.0 (reference) & - & 1.0 (reference) & - \\
\hline
\end{tabular}

$\mathrm{ACE}=$ angiotensin converting enzyme; $\mathrm{ARB}=$ angiotensin receptor blocker; $\mathrm{ASA}=$ aspirin; $\mathrm{BMI}=$ body mass index; $\mathrm{BP}=\mathrm{blood}$ pressure; $\mathrm{BUN}=\mathrm{blood}$ urea nitrogen; $C A D=$ coronary artery disease; $C O P D=$ chronic obstructive pulmonary disease; $C X R=$ chest $x$-ray; $E C G=$ electrocardiogram; $E F=$ ejection fraction; $\mathrm{Hb}=$ hemoglobin; $\mathrm{HCTZ}=$ hydrochlorothiazide; $\mathrm{HF}=$ heart failure; $\mathrm{HJR}=$ hepatojugular reflex; JVD = jugular venous distention; $\mathrm{LBBB}=$ left bundle branch block; LVH = left ventricular hypertrophy; MDRD = Modification of Diet in Renal Disease; MI = myocardial infarction; NYHA $=$ New York Heart Association; PND = paroxysmal nocturnal dyspnea; $W B C=$ white blood cell.

${ }^{*}$ Indicates statistically significant.

\begin{tabular}{lcc}
$\begin{array}{l}\text { Supplemental Table } 3 \\
\text { Year }\end{array}$ & Multivariable Predictors of Death at 1 \\
\hline Variable & Hazard Ratio (95\% CI) & $P$ Value \\
\hline Hepatojugular reflux & $3.5(1.1-11.9)$ & .04 \\
Murmur & $4.8(2.5-9.4)$ & $<.001$ \\
Diastolic blood pressure & $11.8(3.1-44.8)$ & $<.001$ \\
Systolic blood pressure & $0.02(0.003-0.14)$ & $<.001$ \\
PCT & $1.8(1.4-2.3)$ & $<.001$ \\
MR-proANP & $1.8(1.2-2.6)$ & .004 \\
\hline
\end{tabular}

Continuous variables were log-transformed. 